\title{
A formação docente e a atividade de trabalho com adolescentes: diálogos possíveis
}

\author{
Teacher education and work activity with adolescents: possible dialogues \\ Eliéte Zanelato \\ Doutora em Educação \\ Universidade Federal de Rondônia - UNIR. \\ Ariquemes, $\mathrm{RO}-$ Brasil. \\ elietezan@gmail.com \\ Soraya Cunha Couto Vital \\ Mestre em Psicologia \\ Universidade Federal de Mato Grosso do Sul - UFMS. \\ Campo Grande, MS - Brasil. \\ sorayavital@hotmail.com \\ Sônia da Cunha Urt \\ Doutora em Educação \\ Universidade Federal de Mato Grosso do Sul - UFMS. \\ Campo Grande, MS - Brasil. \\ surt@terra.com.br
}

Resumo: No presente ensaio propomo-nos a analisar as relações dialéticas do sujeito professor e sua formação psíquica com o desenvolvimento de sua atividade de trabalho com adolescentes. A fundamentação teórica utilizada nesse estudo está ancorada em textos de Vygotski (1896-1934), Leontiev (1903-1979), Davidov (1930-1998) e autores contemporâneos que interpretam a realidade a partir do Enfoque Histórico-Cultural. Defendemos, ao longo do estudo, que o desenvolvimento da formação docente, constituído a partir de determinações sociais, é também um aspecto determinante da atividade de trabalho do professor. Trabalho esse que pode criar condições de apropriação de conhecimentos que impulsionem o desenvolvimento psíquico dos estudantes adolescentes, e essa dinâmica, por sua vez, possibilita em ambos o desenvolvimento de uma visão mais ampla e crítica da realidade e de si próprios.

Palavras-chave:Enfoque Histórico-Cultural. Formação docente. Desenvolvimento psicológico. Adolescência.

Abstract: In this essay, we propose an analysis of the subject's dialectical relations and his psychic formation with the development of his work activity with adolescents. The theoretical basis used in this study is anchored in texts by Vygotski (1896-1934), Leontiev (1903-1979), Davidov (1930-1998) and contemporary authors who interpret reality from the Historical-Cultural Approach. We defend, throughout the study, that the development of teacher education, constituted from social determinations, is also a determinant aspect of the teacher's work activity. This work can create conditions for the appropriation of knowledge that boost the psychic development of adolescent students, and this dynamic, in turn, makes it possible for both of them to develop a broader and more critical view of reality and of themselves.

Keywords: Historical-Cultural Approach. Teacher education. Psychologicaldevelopment. Adolescence.

Cite como

(ABNT NBR 6023:2018)

ZANELATO, Eliéte; COUTO, Soraya Cunha; URT, Vital Sônia da Cunha. A formação docente e a atividade de trabalho com adolescentes: diálogos possíveis. Dialogia, São Paulo, n. 37, p. 1-14, e18235, jan./abr. 2021. Disponível em: https://doi.org/10.5585/dialogia.n37.18235.

American Psychological Association (APA)

Zanelato, E., Vital, S. C. C., \& Urt, S. C. da. (2021, jan./abr.).A formação docente e a atividade de trabalho com adolescentes: diálogos possíveis. Dialogia, São Paulo, 37, p. 1-14, e18235. https://doi.org/10.5585/dialogia.n37.18235. 


\section{Introdução}

Na busca pela superação da Psicologia metafísica, Vygotski ${ }^{1}$ (1896-1934) se dedicou à criação da Psicologia científica sustentada em pressupostos marxistas. Suas elaborações teóricas e de seus colaboradores deram origem ao que conhecemos hoje como Psicologia Histórico-Cultural. A Teoria da Atividade, compreendida como vertente da Psicologia Histórico-Cultural, é representada por autores como Leontiev (1903-1979), Elkonin (1904-1984) e Davidov (19301998). No presente ensaio compreendemos o grupo de autores supracitados, e outros que utilizaremos ao longo do estudo, como componentes do Enfoque Histórico-Cultural (EHC).

A partir dessa base teórica, compreendemos que, no processo de desenvolvimento histórico, o ser humano age na natureza promovendo modificações que atendam suas necessidades, o que gera mudanças em seu desenvolvimento psíquico. Trata-se de um processo dinâmico, em que a consciência, a partir de determinantes da realidade concreta, se desenvolve e reestrutura seus sistemas complexos, ampliando as condições do sujeito de compreensão da realidade e de si próprio.

Para Leontiev $(1978$, 2004), algumas atividades realizadas ao longo da vida são mais determinantes que outras para o desenvolvimento das funções psíquicas, a saber: na infância, o jogo; na infância e adolescência, o estudo; e na juventude e idade adulta; o trabalho. Nesse aparato, a comunicação também compõe as atividades dominantes de diferentes formas em cada fase do desenvolvimento humano. $\mathrm{O}$ autor se refere à periodização da atividade com base no conceito de atividade dominante/principal, que deve ser compreendido no contexto concreto em que os sujeitos estão inseridos.

Elkonin (1961), no intuito de aprofundar os estudos realizados por Leontiev, esclarece que a periodização da atividade humana ocorre nas atividades de compreensão do objeto de conhecimento e nas relações sociais. Nesse sentido, é por meio dessas atividades dominantes que o indivíduo se apropria do mundo objetivo e delimita continuamente sua personalidade.

Leontiev (2004) aponta a educação dirigida (escolar) como uma das principais responsáveis pela mudança do tipo dominante de atividade, uma vez que ela conduz a uma necessidade interior nova a partir de novas tarefas, cada vez mais complexas, o que gera necessidade de reorganização das condições externas e internas. Ao sujeito adentrar à escola, aos poucos a atividade dominante deixa de ser o jogo e passa ser o estudo. Nesse período, que vai até a adolescência, é pelo estudo

\footnotetext{
${ }^{1}$ Optamos pela grafia Vygotski tal qual aparece nas Obras Escogidas (1996), exceto quando se trata de uma citação direta. Nesse caso permanecerá tal qual publicado pelo autor.
} 
que ocorrem as principais relações com a realidade concreta e, em seguida, pelo trabalho. Isso não significa que são as únicas atividades.

As condições de comunicação também vão se desenvolvendo e possibilitando novas análises e reflexos das relações sociais, assim como novas atitudes diante da realidade. $\mathrm{Na}$ adolescência, a comunicação com os pares/demais adolescentes se torna fundamental na formação da personalidade e na capacidade de compreensão do mundo e de si.

A linha de defesa do EHC - desde a definição de Vygotski (2000), de que a aprendizagem gera o desenvolvimento - é a de que a educação escolar, ao possibilitar o acesso aos conhecimentos produzidos pela humanidade, impulsiona a apropriação de conceitos e a utilização destes como formas de pensamento e de reflexo da realidade e de si mesmo, isto é, possibilita o desenvolvimento do pensamento teórico.

Destacamos, nesse processo, o papel fulcral do professor, por ser o sujeito direcionador e possibilitador das condições necessárias para que os estudantes se apropriem dos conhecimentos e desenvolvam suas funções psíquicas. Entretanto, seu caráter direcionador não significa a passividade dos estudantes diante desse processo, ao contrário, serão sujeitos em ação e movimento.

Nesse sentido, o professor, em sua atividade de trabalho, tem a oportunidade de desenvolver suas próprias funções psíquicas e impulsionar esse desenvolvimento também em seus alunos. Para isso, defendemos que o desenvolvimento da formação docente, constituído a partir de determinações sociais, é também um aspecto determinante da atividade de trabalho do professor. Trabalho esse que pode criar condições de apropriação de conhecimentos que impulsionem o desenvolvimento psíquico dos estudantes adolescentes. Essa dinâmica, por sua vez, possibilita em ambos o desenvolvimento de uma visão mais ampla e crítica da realidade e de si próprios.

Diante do exposto, no presente ensaio propomo-nos a analisar a relação dialética do sujeito professor e sua formação psíquica com o desenvolvimento de sua atividade de trabalho com adolescentes, com especificidade em dois enfoques: a) a formação de professores, a partir do EHC, que proporciona contributo teórico-metodológico para estudar as questões pertinentes à docência a partir da compreensão de que o homem não é um ser passivo, contemplativo, mas sujeito de ação e movimento; b) o trabalho do professor como possibilitador de condições para o desenvolvimento do pensamento teórico dos estudantes adolescentes. 


\section{A formação docente a partir do Enfoque Histórico-Cultural}

Apresentamos esse tópico sob o objetivo de analisar a formação de professores a partir do EHC, que proporciona contributo teórico-metodológico para estudar as questões pertinentes à docência a partir da compreensão de que o ser humano não é um ser passivo, contemplativo, mas sujeito de ação e movimento.

Consideramos, inicialmente, que a concepção de professor na perspectiva histórico-cultural é de agente organizador de possibilidades para o desenvolvimento, para a apropriação dos conhecimentos, o que propõe desafios aos alunos e, com suas intervenções, ajuda-os a resolvê-los. Com sua atuação, contribui para o fortalecimento de funções ainda não consolidadas ou para a abertura de zona de desenvolvimento iminente ${ }^{2}$.

Com o respaldo do EHC, Urt (2012) declara que o trabalho do professor é formado por seu objetivo de ensinar. Consciente das condições reais e objetivas do processo ensinoaprendizagem, sua finalidade é fazer com que o aluno se aproprie do conhecimento. A mesma autora considera que, no sentido subjetivo do trabalho docente, é preciso atentar para o que motiva tal trabalho, ou seja, qual o sentido pessoal da atividade para o professor:

A unidade básica do trabalho docente seria o sentido que têm para o professor as ações que ele realiza em seu trabalho. Quando o sentido pessoal do trabalho do professor separa-se do significado dado socialmente, pode considerar-se que esse trabalho é alienado e descaracteriza a prática educativa escolar. (URT, 2012, p. 32).

Vygotski (1987) e Leontiev (2004) defendem a essência sociocultural do homem e a importância da socialização para o desenvolvimento pleno de suas potencialidades. Seus pressupostos defendem que o homem é um ser social, produto da vida em sociedade e da apropriação da cultura, mas é necessário que passe por um processo denominado humanização, a fim de que possa tornar-se verdadeiramente homem. Ou seja, precisa passar por um processo histórico-cultural de transmissão das características do gênero, em que cada indivíduo se aproprie dos conhecimentos, valores e comportamentos produzidos por seu grupo, para humanizar-se. Vygotski (1987) e Leontiev (2004) evidenciam então que aessência humana é uma essência histórica ou histórico-social.

Segundo Leontiev (2004), as aquisições do desenvolvimento histórico das aptidões humanas não são dadas aos homens, estas são apenas postas, e para haver a apropriação desses resultados, para que haja a objetivação da cultura que o encarna, o homem necessita da

\footnotetext{
${ }^{2}$ Prestes (2010), em sua obra 'Quando não é Quase a Mesma Coisa', considera que Vygotski não utilizou o termo 'zona de desenvolvimento proximal', e sim 'zona de desenvolvimento iminente', e que este seria mais um equívoco de tradução de seus textos.
} 
intermediação de outros homens, entrando em relação com os fenômenos circundantes em um processo de comunicação uns com os outros.

Contudo, vale ressaltarmos que o movimento da história só é possível a partir da transmissão das aquisições da cultura humana às novas gerações.Essa forma particular de fixação e transmissão das aptidões humanas se deve à sua atividade fundamental: o trabalho.

Para Leontiev (1978), a origem das funções psíquicas humanas situa-se no processo de interiorização da atividade externa, que é transformada em atividade interna. Nesse processo, a consciência só existe nas condições de uma consciência social e, ao apropriar-se dos conhecimentos e da cultura, o homem passa da consciência social para a individual. A atividade é a mediadora de todo esse processo dinâmico.

Essa passagem do social para o individual acontece, segundo ele, pela apropriação dos significados sociais constituídos pela linguagem, o que lhe confere um sentido próprio, um sentido pessoal, ligado aos sentimentos, motivos e necessidades. Existe, então, uma relação entre significado social e sentido pessoal, que são componentes da estrutura da consciência.

Vygotski (1987), sob sua perspectiva histórico-cultural, postula que o desenvolvimento biológico e histórico do ser humano, consubstanciados na filogênese e na ontogênese, revelam diferenças entre espécie e gênero humano. Nesse sentido, hominização e humanização constituem aspectos distintos da processualidade humana, ou seja, uma vez constituído o homo sapiens abremse novas necessidades e novas possibilidades, as quais, por meio do trabalho e dos complexos sociais dele decorrentes, tornam possível a consolidação do homem como ser social.

Salientamos, porém, que o conceito de trabalho aqui explicitado não está associado ao sentido de emprego ou identificado pela relação empregatícia, na forma social do capital, mas concebido.

[...] como atividade vital do homem, diferenciada da atividade dos animais, por ser mediada pela reflexão consciente, livre e por produzir incessantemente o novo, gerando a partir dele novaspossibilidades, necessidades e habilidades ao gênero humano, concepção sustentada por Marx. (BESERRA et al., 2009, p. 01).

Duarte (2012) reitera a importância da base marxista para as postulações da Teoria da Atividade, ao explanar que os estudos de Leontiev $(1978,2004)$ apontam na direção da articulação da atividade essencialmente social dos seres humanos com os processos de formação da consciência, tanto no sentido da formação humanizadora da consciência como no sentido alienante da mesma.

Nesse contexto, há que se considerar que a formação do professor está intimamente relacionada à prática pedagógica, portanto, para analisá-la, é preciso discutir sua função educativa, 
seu papel possibilitador em um contexto mediador de um projeto de sociedade que tanto pode ser conservador quanto transformador.

Duarte (2016, p. 65) considera que o trabalho educativo, no qual estão inseridas a formação e a atuação do professor, deve apresentar continuamente a luta pela superação da alienação, proposta pelo "aprender a aprender" ou "fazer pelo fazer", e tecer análises pautadas na "dialética que está latente nos escritos de Marx", a fim de que haja entendimento de que "não há criação do novo sem apropriação do que já existe”.

Segundo o Enfoque Histórico-Cultural, os processos relativos à educação são contínuos e têm experimentado significativas transformações. Em decorrência disso, apresenta necessidade premente de compreensão de seus alicerces, conceitos e modalidades. A formação de professores não está à margem de taismetamorfoses e, por esse motivo, também requer entendimento amplo de seus fundamentos e abordagens.

Sendo assim, a partir desse aporte teórico a formação docente é vista sob o entendimento de que o ser humano é histórico, sujeito da ação, sempre em transformação, que se constitui por meio das relações socioculturais e desassemelha-se dos animais por sua capacidade de transformar a natureza por meio de seu trabalho.

A esse respeito Duarte (2012) considera que

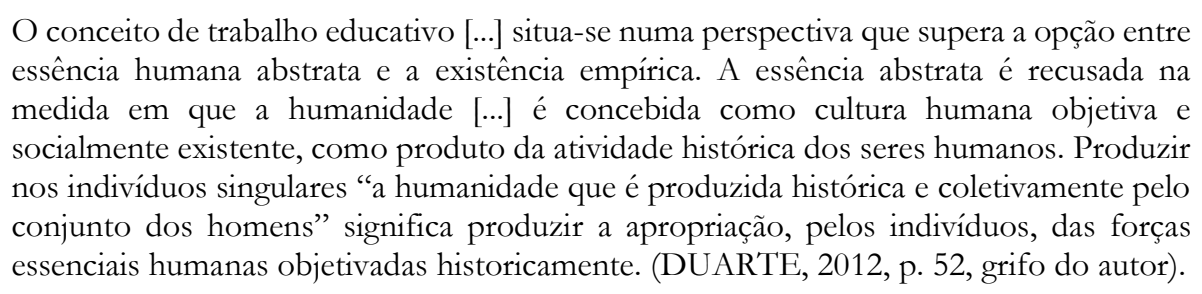

A partir dessa premissa, podemos considerar também o entendimento do EHC acerca do trabalho e da formação docente, que reúne elementos a respeito da função da escola e de compreensão da relação existente entre aprendizagem e desenvolvimento, evidenciando que o papel da aprendizagem é precedente ao desenvolvimento, invertendo a concepção naturalista.

Esse arcabouço teórico estabelece ao professor uma nova relação com os processos de educação e de ensino e, consequentemente, um novo olhar sobre sua responsabilidade e papel no desenvolvimento das qualidades humanas, visto que educação e ensino são transformados em possibilidades universais do desenvolvimento humano.

Acreditamos oportuno considerar que, para pensar os processos de ensino e aprendizagem que devem acontecer na escola, é imprescindível refletir sobre a função, a formação e a valorização do professor como agente primordial no processo formativo do sujeito, tecendo questões relativas 
à estrutura educativa capaz de dar suporte e englobar a transição de paradigma que o debate acerca da educação pressupõe.

Um dos principais impasses é a falta de formação histórico-crítico-social e valorização profissional, causando um impacto negativo na educação. Não basta oferecer uma formação se esta for alheia ao contexto mais amplo da sociedade, por exemplo, porque a priori deve estar articulada a um projeto educativo bem definido, que possibilite aos professores o entendimento de suas tarefas (SILVA; SILVA, 2012).

Outro aspecto que consideramos pertinente, é que se o trabalho do professor e a sua formação estão intimamente relacionados à escola; a primeira premissa para pensar e elaborar um projeto de formação de professores é discutir a função da escola na sociedade. A escola é uma instância e uma instituição social, dentre outras, que tem um papel mediador em um projeto de sociedade, que tanto pode ser conservador quanto transformador, por isso também contraditório entre formar para o mercado de trabalho ou numa perspectiva omnilateral (SILVA, 2014).

Para Saviani (2003, p. 21), a formação docente deve ser tomada numa visão de totalidade, na relação trabalho, escola, educação e na conexão com o todo social. Está diretamente relacionada à função da escola como possibilidade emancipatória do sujeito. O trabalho educativo do professor “[...] é o ato de produzir, direta e intencionalmente, em cada indivíduo singular, a humanidade que é produzida histórica e coletivamente pelo conjunto dos homens".

Diante do exposto, cabe reputar que o Enfoque Histórico-Cultural defende uma escola que, de forma socializada, transmita os conhecimentos científicos produzidos historicamente, com qualidade, com métodos avançados, e que sua concepção de professor é a de agente possibilitador do processo de aprendizagem.

Esse Enfoque também assevera que a atividade docente, seu trabalho, não é um objeto físico, mas é revelado quando promove a humanização dos sujeitos-discentes a partir de ações promotoras de aprendizagem que contribuam para que se apropriem dos conhecimentos historicamente acumulados e sistematizados pelo gênero humano. Logo, reputamos aqui que a formação docente precisa ser pensada e realizada com base no pressuposto de que os alunos/estudantes dependem do trabalho professoral e da organização do ensino para se desenvolverem. Essa será a tratativa do tópico a seguir. 


\section{Implicações pedagógicas para a formação do pensamento teórico do adolescente}

Com base no já exposto, reiteramos que o ser humano se constitui como tal por meio da atividade, se apropriando dos conhecimentos produzidos e desenvolvendo suas funções psíquicas em um processo contínuo. No caso do professor, sua atividade de trabalho é a práxis pedagógica e sua constituição docente ocorre na atividade de ensino, que precisa considerar forma, conteúdo e destinatário (MARTINS, 2011). Logo, o trabalho do professor precisa envolver elementos relacionados à organização didática a ser utilizada, ao conteúdo a ser ensinado e a compreensão acerca do destinatário (estudante). Isto é: O que ensinar? Para quem ensinar? Como ensinar? Por que ensinar?

No presente tópico voltaremos o olhar ao destinatário adolescente, com o objetivo de estudar o trabalho do professor como possibilitador de condições para o desenvolvimento do pensamento teórico desses estudantes.

Durante a adolescência, a atividade dominante tende a ser o estudo e as relações com os pares, mas, à medida que os sujeitos adolescentes se aproximam do final do Ensino Médio, a atividade de estudo vai se voltando cada vez mais para uma atitude séria perante o trabalho futuro.

Para o Enfoque Histórico-Cultural, as modificações ocorridas nas relações sociais impulsionam a mudança no sistema de interesses dos sujeitos, por isso a criança, ao entrar no Ensino Fundamental, passa a ter mais responsabilidades para com o estudo. Já na adolescência a liberdade do sujeito é ampliada e, com isso, o círculo social também; assim amplia-se a responsabilidade pela determinação de uma profissão futura ou mesmo pela busca de um sustento imediato. Enfim, são inúmeras situações da realidade concreta que são refletidas consciente e ativamente de diferentes maneiras pelos sujeitos ao longo de sua vida.

Vygotski (1996) destaca três pontos de maturação que servem de base para a compreensão das peculiaridades e contradições da adolescência: sexual, orgânica geral e social. As mudanças orgânicas e sexuais são mais fáceis de ser percebidas nos e pelos adolescentes. Nas relações sociais percebem-se "não crianças", pela posição que ocupam, pelas tarefas a eles atribuídas e pela forma como são tratados pelos adultos. As mudanças orgânicas, sexuais e sociais pelas quais passam os adolescentes estão interligadas e alteram seus interesses e a imagem que possuem de si mesmos (autoconsciência).

Para Leontiev (2004), a adolescência é marcada pelo aumento da criticidade nas relações sociais nas quais os indivíduos se incluem e pela ampliação destas. Destaca que nessa fase aparecem interesses verdadeiramente teóricos pela primeira vez, concordando com os escritos de Vygotski (1996). 
O período da adolescência, de acordo com Vygotski (1996), marca o início da assimilação do processo de formação de conceitos - nova e superior forma de atividade intelectual - um processo qualitativamente mais complexo. O conteúdo do pensamento do adolescente está ligado diretamente às formas realmente novas da atividade intelectual. Ele passa a perceber o mundo da consciência social objetiva e o mundo da ideologia social.

Para Vygotski (1996, p. 59), a formação de conceitos é o "núcleo fundamental que aglutina todas as mudanças que se produzem no pensamento do adolescente". O pensamento por conceitos é uma nova forma de organização psíquica do sujeito, é uma nova forma de intelecto, muda o conteúdo do seu pensamento. É a forma que possibilita uma compreensão mais ampla da realidade concreta do adolescente e permite perceber as múltiplas conexões e abstrações dessa realidade.

$\mathrm{Na}$ concepção de Vygotski (1996, p. 82), o pensamento lógico “está constituído pelos próprios conceitos em ação e funcionamento". O autor (1996, p. 113) ainda complementa que, nessa fase, o desenvolvimento do pensamento possui “um significado central, básico, decisivo para todas as funções e processos restantes".

A partir do sucesso no desenvolvimento do pensamento do adolescente, todas as demais funções psíquicas se reestruturam e impulsionam a sua visão de mundo e de si mesmo (elaboração de sínteses superiores), utilizando para isso o pensamento lógico. Com as novas e superiores possibilidades de reflexos conscientes da realidade e de si a personalidade do adolescente é alterada.

Segundo Elkonin (1961), as capacidades psíquicas também alcançam seus níveis mais altos na atividade de trabalho, mas isso depende de como foi o processo de desenvolvimento psíquico nas atividades anteriores. A atividade de estudo, se sistematizada e direcionada para a apropriação dos conhecimentos mais bem elaborados da humanidade (conhecimentos científicos, artes e filosofia), possibilita o desenvolvimento de tais capacidades consolidando o pensamento teórico, ou seja, o pensamento que opera por conceitos.

Davidov (1988) faz, resumidamente, uma análise comparativa entre o conhecimento empírico e o conhecimento teórico, com seis itens principais. Para ele, o termo conhecimento engloba: abstrações, generalizações e conceitos. Apresentaremos em forma de quadro para melhor visualização do conteúdo. 
Quadro 1 - Comparação entre conhecimento empírico e teórico

\begin{tabular}{|c|c|c|}
\hline & Conhecimentos empíricos & Conhecimentos teóricos \\
\hline 1 & $\begin{array}{l}\text { São elaborados no processo de comparação } \\
\text { dos objetos e das representações sobre eles, o } \\
\text { que permite separar as propriedades iguais, } \\
\text { comuns. }\end{array}$ & $\begin{array}{l}\text { Surgem no processo de análise do papel e da função } \\
\text { de certa relação peculiar dentro do sistema integral } \\
\text { que, ao mesmo tempo, serve de base genética inicial } \\
\text { de todas as suas manifestações. }\end{array}$ \\
\hline 2 & $\begin{array}{l}\text { No processo de comparação, tem lugar a } \\
\text { separação da propriedade formalmente geral de } \\
\text { certo conjunto de objetos, o conhecimento do } \\
\text { qual permite referir objetos isolados a uma } \\
\text { classe determinada, independentemente de } \\
\text { estarem ou não vinculados entre si. }\end{array}$ & $\begin{array}{l}\text { O processo de análise permite descobrir a relação } \\
\text { geneticamente inicial do sistema integral como sua } \\
\text { base universal ou essência. }\end{array}$ \\
\hline 3 & $\begin{array}{l}\text { Ao se apoiar nas observações, refletem em } \\
\text { representações as propriedades externas dos } \\
\text { objetos. }\end{array}$ & $\begin{array}{l}\text { Surgem sobre a base da transformação mental dos } \\
\text { objetos, refletem suas relações e conexões internas, } \\
\text { "saindo" assim dos limites das representações. }\end{array}$ \\
\hline 4 & $\begin{array}{l}\text { Formalmente a propriedade geral separa-se } \\
\text { como algo pertencente à mesma ordem que as } \\
\text { propriedades particulares e singulares dos } \\
\text { objetos. }\end{array}$ & $\begin{array}{l}\text { Fixa o enlace da relação universal, realmente } \\
\text { existente, do sistema integral com suas manifestações, } \\
\text { o enlace do universal com o singular. }\end{array}$ \\
\hline 5 & $\begin{array}{l}\text { Seu processo de concretização consiste em } \\
\text { selecionar ilustrações, exemplos, que entram na } \\
\text { correspondente classe de objetos. }\end{array}$ & $\begin{array}{l}\text { Seu processo de concretização consiste na dedução e } \\
\text { explicação das manifestações particulares e singulares } \\
\text { do sistema integral a partir de seu fundamento } \\
\text { universal. }\end{array}$ \\
\hline 6 & $\begin{array}{l}\text { As palavras-termos são o meio indispensável } \\
\text { para fixar os conhecimentos empíricos. }\end{array}$ & $\begin{array}{l}\text { Expressam-se nos procedimentos da atividade } \\
\text { mental e, posteriormente, com a ajuda de diferentes } \\
\text { meios simbólicos e semióticos, em particular as } \\
\text { linguagens natural e artificial. }\end{array}$ \\
\hline
\end{tabular}

Fonte: Adaptado do texto de Davidov (1988, p. 154-155). Comparação entre conhecimento empírico e teórico.

Podemos verificar que, para operar com o conhecimento teórico em sua complexidade, são necessárias funções psíquicas muito mais desenvolvidas do que as necessárias para operar com os conhecimentos empíricos. A escola, lugar que as crianças e adolescentes frequentam constantemente e que possui, ou deveria possuir, a aprendizagem como função social, pode contribuir para a apropriação de conhecimentos teóricos e criar condições para que os estudantes desenvolvam o pensamento teórico.

Isso também exige do professor o desenvolvimento de seu pensamento teórico, para que possa planejar e executar a atividade de ensino (seu trabalho) de forma a utilizar e propor situações de utilização dos conhecimentos teóricos. Davidov (1988) defende que o ensino que impulsiona o desenvolvimento mental dos estudantes é aquele que promove o processo de elevação do abstrato ao concreto, de tal forma que seja possível a apropriação do conceito em seu processo lógico e histórico. 
O autor defende que, na atividade de estudo, ao se apropriar dos conhecimentos, o estudante reproduza de maneira abreviada o processo histórico real de geração e desenvolvimento desses conhecimentos. Ou seja, o conceito deve ser compreendido em seu processo lógico e histórico, não de maneira pronta e acabada, como ocorre na escola tradicional (DAVIDOV, 1988).

Cabe destacarmos que o concreto é compreendido pelo autor na concepção materialista histórica e dialética, isto é, como a essência do objeto de conhecimento, pautado em suas múltiplas relações de generalidades, e não como algo palpável. Para Davidov (1988, p. 146-147), a essência do objeto de conhecimento, ou da coisa, "pode ser descoberta apenas no exame do processo de desenvolvimento de dita coisa. [...] A essência é a conexão interna que, como fonte única, como base genética, determina todas as outras especificidades particulares do todo”.

No Enfoque Histórico-Cultural, a atividade de trabalho do professor possui uma função primordial para o processo de estudo dos estudantes. Não é, porém, uma tarefa fácil. Ao contrário, exige muito do professor, que precisa ter se apropriado dos conhecimentos teóricos que vai ministrar. Além disso, precisa conduzir a atividade de ensino de forma a criar as condições de apropriação, pelos estudantes, dos conteúdos teóricos em seu processo de geração e desenvolvimento, de maneira a impulsionar as capacidades de desenvolvimento do pensamento teórico. Para isso, o professor ainda precisa conhecer as especificidades dos destinatários, os estudantes adolescentes em suas situações concretas de vida.

Cabe destacar que apresentamos aqui algumas determinações gerais do período da adolescência, principalmente relacionadas à capacidade de desenvolvimento de conceitos, e evidenciamos que é um processo e que depende das condições sociais desses sujeitos.

Reiteramos, então, que o desenvolvimento do pensamento teórico no adolescente é dependente das apropriações já realizadas por esses sujeitos ao longo de sua vida, principalmente na atividade de estudo. É dependente das possibilidades criadas para o desenvolvimento de suas operações mentais. Nesse sentido, as diferenças existentes entre os adolescentes comumente não se devem às questões biológicas, mas sociais e de acesso aos conhecimentos teóricos.

\section{Considerações finais}

No presente trabalho o objetivo foi analisar as relações dialéticas do sujeito professor e sua formação com o desenvolvimento de sua atividade de trabalho com adolescentes. Buscamos defender, ao longo do ensaio, que o desenvolvimento da formação docente, constituído a partir de determinações sociais, não é o único, mas é também um aspecto determinante da atividade de trabalho do professor. 
Com base no Enfoque Histórico-Cultural e seus autores clássicos é possível compreender que o ser humano é social e se constitui como tal a partir do trabalho e, concomitantemente, da linguagem. Essa última é o que possibilita ao sujeito a apropriação da cultura produzida pelas gerações anteriores, visto que dá condições para que os objetos externos sejam refletidos no psiquismo humano, tornando-os conceitos.

A formação docente, relacionada à atividade de trabalho do professor, pode e deve proporcionar meios de desenvolvimento de sua formação psíquica e as condições de objetivação para uma prática pedagógica que impulsione também o desenvolvimento psíquico dos estudantes adolescentes, oportunizando condições para uma visão mais ampla e crítica da realidade e de si próprios.

Para isso, tal como defende o enfoque aqui adotado, é preciso romper com modelos estereotipados de educação e assumir propostas e projetos de formação docente que possibilitem novos modos de aquisição de conhecimento, de pensar e de agir. Que rompam com uma visão estreita de ensino e se pautem em princípios que concebem o sujeito em sua totalidade, dando suporte ao desenvolvimento da autonomia docente e discente, e trabalhando na contramão do ensino e da aprendizagem espontaneísta e/ou conteudista.

Tal premissa remete ao sentido de superação da fragmentação do próprio ser humano, o que pressupõe a ausência de hierarquias no interior da escola e na formação do profissional docente. Em qualquer escola e em qualquer momento histórico, cabe aos professores a capacidade de propor articulação como meio do conhecimento abrangente, integral e a partir de experiências diversas, considerando que não há um único modo de ensinar e aprender.

No caso específico do adolescente, cabe ao professor considerar as condições concretas em que tais sujeitos estão se constituindo em seu estudo e em sua comunicação com os pares, e oportunizar o acesso aos conhecimentos teóricos produzidos pela humanidade em suas mais ricas expressões. Essa prática poderá possibilitar o desenvolvimento de suas funções psíquicas superiores e a capacidade de pensar por conceitos. De acordo com o Enfoque Histórico Cultural, isso proporcionará uma ampliação da capacidade de compreensão de mundo (conhecimento do objeto) e de si próprios (personalidade).

Consideramos, contudo, que essa realidade não se dará sem um investimento sério nas políticas de formação de professores, tanto inicial quanto continuada, de forma a garantir que tais sujeitos se apropriem da riqueza cultural produzida pela humanidade e operem com o pensamento teórico em seus processos de interpretação da realidade e de si. Tampouco se dará sem uma melhoria nas condições de trabalho do professor e de estudo dos discentes. 


\section{Referências}

BESERRA, F. D. M. et al. A contribuição da teoria de Leontiev no estudo da relação entre trabalho e educação. XV Encontro Nacional da Associação Brasileira de Psicologia Social. Maceió, AL: ABRAPSO, 2009. p. 1-10.

DAVIDOV, V. V. La enseñanza escolar el desarrollo psíquico: investigación teórica y experimental. Madrid-ES: Progreso, 1988.

DUARTE, N. A ontologia do ser social e a pedagogia histórico-crítica. In: SAVIANI, D.; DUARTE, N. Pedagogia histórico-crítica e luta de classes na educação escolar. Campinas, SP: Autores Associados, 2012. p. 52-69.

DUARTE, N. Os Conteúdos e a Ressurreição dos Mortos: contribuição à teoria histórico-crítica do currículo. Campinas, SP: Autores Associados, 2016.

ELKONIN, D. B. Desarrollo Psiquico de los Niños. In: SMIRNOV, A. A. E. A. Psicologia. Havana, Cuba: Imprensa Nacional de Cuba, 1961. p. 493-559.

LEONTIEV, A. N. Actividad, consciência y personalidade. Buenos Aires, Arg.: Ediciones Ciências del Hombre, 1978.

LEONTIEV, A. N. O desenvolvimento do psiquismo. São Paulo, SP: Centauro, 2004.

MARTINS, L. M. O desenvolvimento do psiquismo e a educação escolar: contribuições à luz da psicologia histórico cultural e da pedagogia histórico-crítica. Tese de Livre-Docência em Psicologia da Educação. Universidade Estadual Paulista, Campus de Bauru - SP, 2011. Disponível em: https://formacaodocente.files.wordpress.com/2012/09/martins_ligia_-

_o_desenvolvimento_do_psiquismo_e_a_educacao_escolar.pdf. Acesso em: 19 dez. 2019.

PRESTES, Z. R. Quando Não é Quase a Mesma Coisa:Análise de Traduções de Lev Semionovitch Vigotski no Brasil.Brasília, DF. 2010.

SAVIANI, D. Da nova LDB ao novo plano nacional de educação: por uma outra política educacional. Campinas, SP: Autores Associados, 1998.

SAVIANI, D. Pedagogia Histórico-Crítica: primeiras aproximações. São Paulo, SP: Autores Associados, 2003.

SILVA, J. A. D. A. D.; SILVA, K. N. P. Educaşão Integral no Brasil de Hoje. Curitiba,PR: CRV, 2012.

SILVA, K. A. C. P. C. A Formação de Professores para a Educação Integral na Escola de Tempo Integral: Impasses e Desafios. In: ROSA, S. V. L.; BRANDÃO, A. A. (Orgs.). Educaşão Integral e Escola Pública de Tempo Integral: formação de professores, currículo e trabalho pedagógico. Goiânia, GO: Gráfica e Editora América, 2014. p. 15-32.

URT, S. D. C. A constituição do sujeito por meio da apropriação da cultura e da educação: o foco na atividade docente. In: URT, S. D. C.; CINTRA, R. C. G. (Orgs).Identidade, Formação e Processos Educativos. Campo Grande, MS: Life, 2012. p. 30-43. 


\section{Dialogia}

ZANELATO, Eliéte; COUTO, Soraya Cunha; URT, Vital Sônia da Cunha. A formação docente e a atividade de trabalho com adolescentes: diálogos possíveis

VYGOTSKI, L. S. Obras Escogidas (Tomo IV). Madrid, Espanha: Visor Distribuciones, 1996.

VYGOTSKI, L. S. Psicologia concreta do homem. Educação \& Sociedade, Centro de Estudos Educação e Sociedade(CEDES), ano XXI, nº 71, p. 21-44, 2000. [on line]. Disponivel em: http://www.scielo.br/pdf/es/v21n71/a02v2171.pdf. Acesso em: 10 abril 2019.

VYGOTSKY, L. S. A Formação Social da Mente. São Paulo, SP: Martins Fontes, 1987. 